\title{
Design and Control of Space Vector Pwm Technique with the Fuzzy Control Based Multilevel Inverter for an open end Winding Induction Motor
}

\author{
B.Nageswararao, Ch.Divyakrishna, T.Anil Kumar
}

\begin{abstract}
In this paper the three phase open end winding IM drive is designed and controlled using a fuzzy control based multilevel inverter with SVM technique is proposed. To overcome the disadvantages of PI controller, in this project we are using the fuzzy controller. The fuzzy controller rules are analyzed very easily, because of it is a human decision making system. The traditional dual inverter having two dc sources the cost and size is might be high, so to overcome this we use the proposed method with single dc voltage source. The main objective of the proposed method is to eliminate the transformer. To achieve the multilevel output voltage waveform with three levels a dc voltage ratio 2:1 is used. The space vector PWM is used to control the switching states of dual multilevel inverter. The fuzzy controller implementation cost is less and more precise. The simulation results are used to analyze the proposed method with fuzzy controller.
\end{abstract}

Key words: Multilevel inverter, field-orientated controller (FOC), floating bridge, SVM pulse width modulation, Fuzzy controller, $\mathrm{OEW}$ induction motor.

\section{I.INTRODUCTION}

Nowadays, the multilevel converters are used mostly in this world with these advantages.

i. The output voltage waveform is achieved.

ii. The distortions is reduced.

iii. The $\mathrm{dv} / \mathrm{dt}$ ratio is decreased.

Multilevel converters are categorized into mainly three types. i.e the cascaded H-bridge, the flying capacitor and the diode point clamped multilevel inverter.

The traditional block diagram of OEW induction motor drive is shown in fig.1.

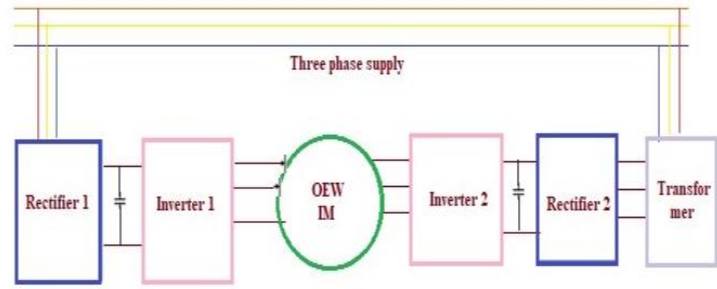

Fig.1. The block diagram of Traditional OEW IM drive.

In this project dual two level inverter is used. The dual inverters are more reliable because if any one of the inverter is failed then other inverter will be operated as single three-phase inverter.

\footnotetext{
Revised Manuscript Received on December 30, 2019.

* Correspondence Author

B.Nageswararao, Assistant Professor, Eee Department, Anurag Group Of Institutions

Ch.Divyakrishna, M.Tech (Peed), Eee Department, Anurag Group Of Instituions

Dr. T.Anil Kumar, Professor, Hod, Eee Department, Anurag Group Of Institutions
}

(C) The Authors. Published by Blue Eyes Intelligence Engineering and Sciences Publication (BEIESP). This is an open access article under the CC BY-NC-ND license (http://creativecommons.org/licenses/by-nc-nd/4.0/)
Usually, two sources are connected to dual inverter. So, the price and size might to be high. To overcome this disadvantage we can proposed this technique with a single dc voltage source and the use of fuzzy controller.

In this paper a single source is connected to OEW induction motor drive with dual inverter. The primary inverter is connected to voltage source, the second one is connected to capacitor bank as shown in below fig. 2 .

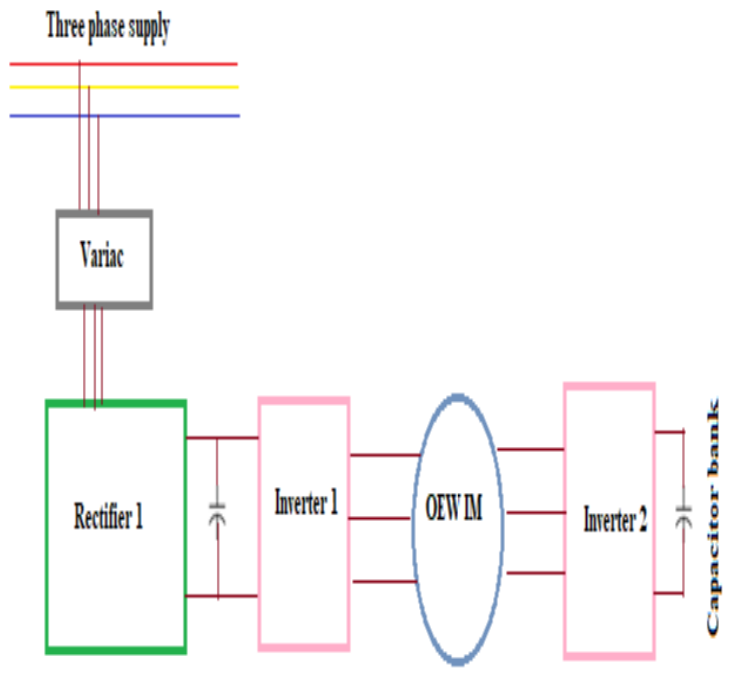

Fig. 2. The block diagram of proposed method with floating bridge capacitor.

The isolation transformer is used to attain the multilevel output voltage waveform. However, the cost and size might be high. The primary goal of this paper is to remove the isolation transformer. The SVM is used to govern the capacitor voltage and eliminate the unwanted voltages.

\section{II.PROPOSED METHOD}

\section{A. Floating capacitor bridge}

The proposed method is having a floating capacitor bridge is connected to open end winding IM drive with a dual two level inverter. It is used to supply reactive power to a motor and to reduce the voltage drop at load side. The three level output voltage waveform is produced with $2: 1 \mathrm{dc}$ voltage ratio. The proposed topology with 2:1 dc voltage ratio is shown in fig.3. 

an Open End Winding Induction Motor

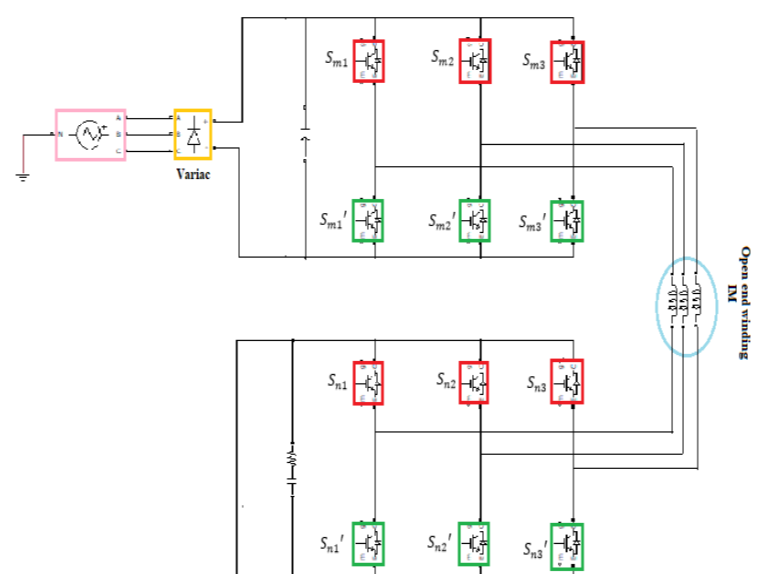

Fig.3. The block diagram of proposed method with 2:1 dc voltage ratio.

Let us consider the phase leg will be inside the line, the top switches will be turned ON ( $\mathrm{sm} 1$ and sn1) then load current will be flows from sm1 and diode dn1. If the bottom switches will be turned ON (sml' and sn1') then current flow from $\mathrm{dm} 1$ and $\mathrm{sn} 1$. In the one leg the both switches are turned $\mathrm{ON}$ at the same time, the current direction will changed. To overcome this drawback firstly, the main converter is operated and then second one is operated.

Different modes of operations are implemented at dead time interval, the voltage levels will be varied. To overcome the drawback, first we operate the main converter next second converter.

A generalized solution for positive load current is shown in figure.4, depending on the switching states the pulses are analyzed.

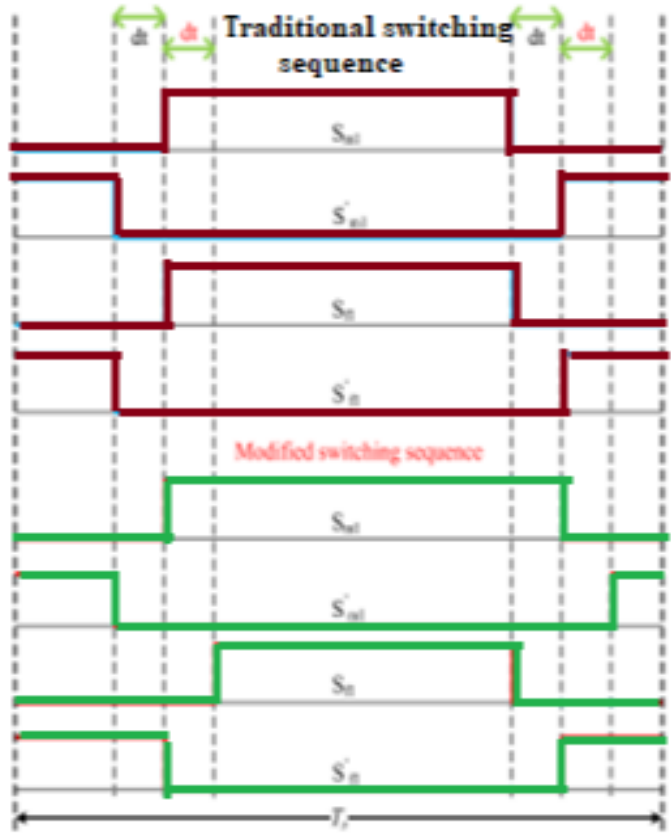

Fig. 4. At the dead time interval, the positive current direction in both converters

The proposed method is used to avoid the unwanted voltage levels and distortions for positive and negative load current it will be shown in Table.1.

TABLE I

SWITCHING STATES OF DUAL INVERTERS

\begin{tabular}{|c|c|c|c|c|}
\hline & $\begin{array}{c}\text { Inv-1 } \\
\text { Top }\end{array}$ & Inv-1 Bot & $\begin{array}{c}\text { Inv-1 } \\
\text { Top }\end{array}$ & $\begin{array}{c}\text { Inv-1 } \\
\text { Bot }\end{array}$ \\
\hline $1>0$ & Tum off & Turn on & Tum on & Tum off \\
\hline $1<0$ & Tum on & Turn off & Tum off & Tum on \\
\hline
\end{tabular}

During the dead time the current direction is not changed with the modified switching sequences.

\section{B. Principles of operation}

The SVM is used to analyze the switching states of dual inverter, due to this switching pulses the capacitor is charge and discharged. The space vector pulse width modulation diagram is shown in fig.5.

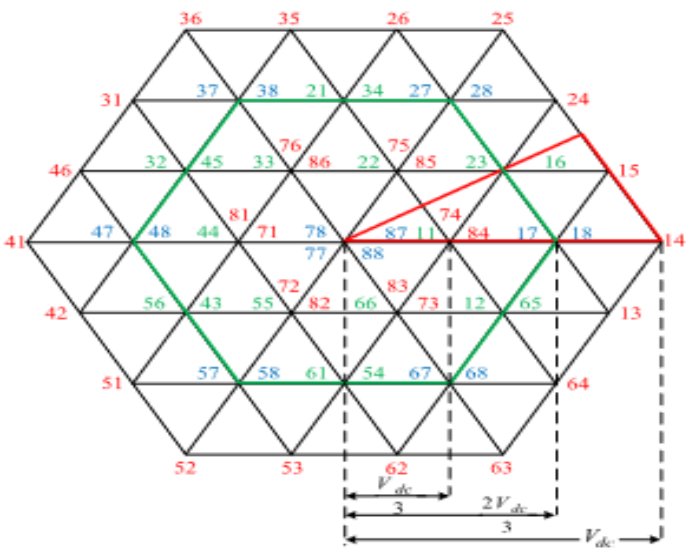

Fig. 5(a). The SVM of dual two -level inverter

The floating capacitor is charged when green numbered switching states are $\mathrm{ON}$, and it will discharged when the red combination switching states are ON. It will be neutral when the blue switching combinations are $\mathrm{ON}$.

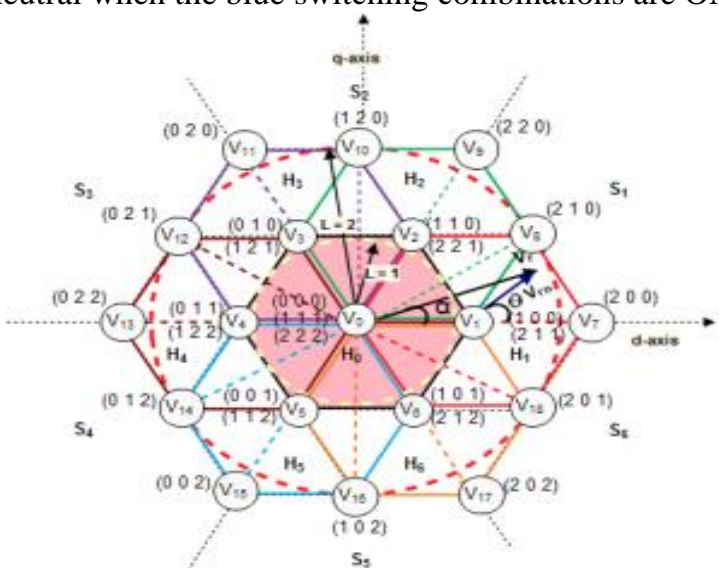

Fig. 5(b) SVM modulation switching combinations

The switching states of the space vector modulation technique as shown in Fig.5(b). At induction load, the capacitor discharged. If the modulation index is 0.66 then the floating capacitor voltage will be half of the main DC link capacitor voltage.

$$
\mathrm{M}=0.66
$$

The switching states of both converters is analyzed is shown in fig.6.

For example we consider the switching state of (74), 7 (1 1 1) - it will represents main converter top three switches and $4\left(\begin{array}{lll}0 & 1 & 1\end{array}\right)$ - it will represents floating capacitor top three switches. If the combination of switching states (11) and (16) are charge the capacitor.

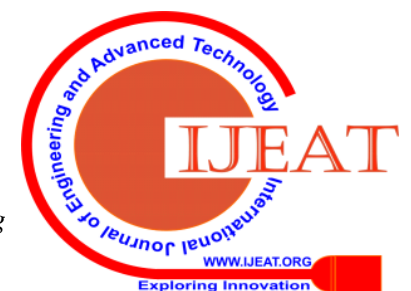




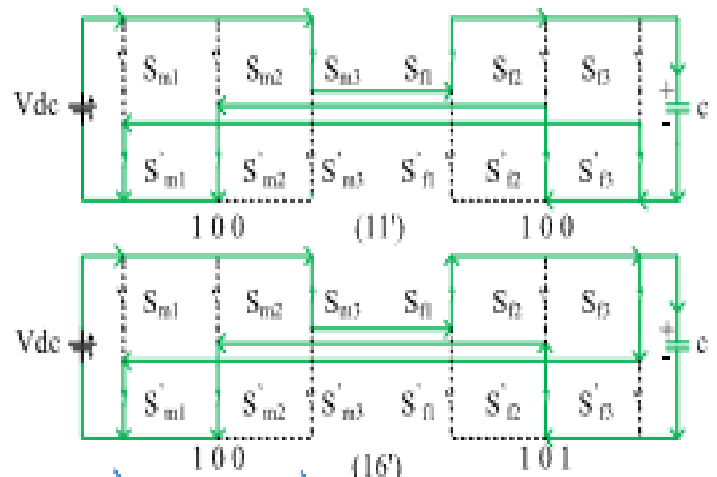

Fig.6. switching states for positive current direction The capacitor is discharged when the combinations of (14) (15) and (74) switching states are ON. It passes the direct current from negative terminal to positive terminal of the capacitor

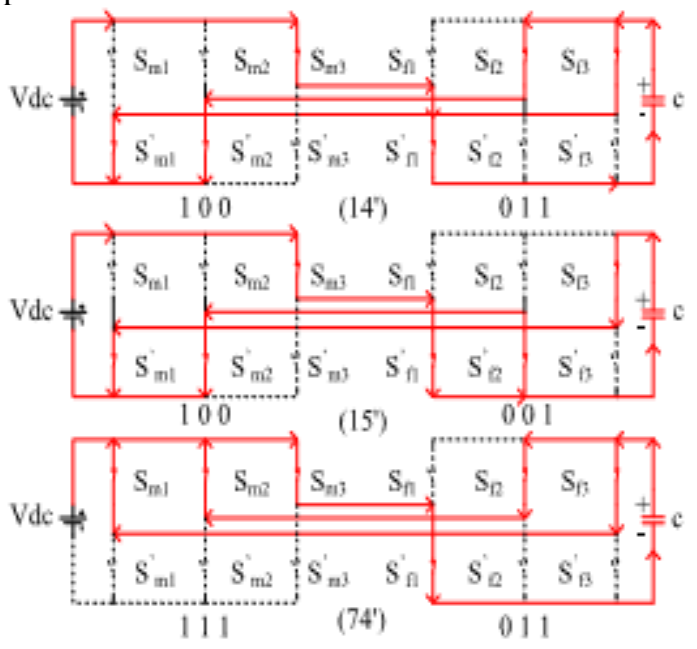

Fig.6. switching states for negative current direction

Combinations 7(l 111 ) and 8(l $\left.\begin{array}{lll}0 & 0\end{array}\right)$ are both zero states, the switching states will not shown any impact on the capacitor voltage.

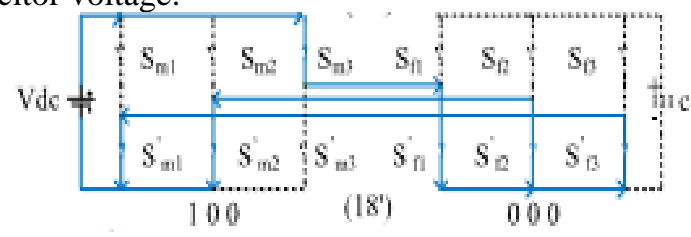

Fig.6. Current flow for zero switching states.

\section{Modulation strategy.}

Dual inverter floating bridge topology has been analyzed with decoupled space vector modulation strategy. By using the switching combinations voltage will be produced which is 180 degrees phase shifted from the other, which is represented in fig.7(a)
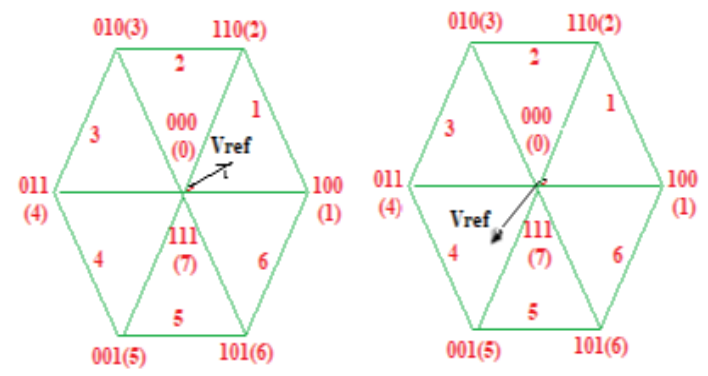

Fig. 7(a) The SVM technique of Individual diagrams of converter
To match the overall voltage reference will add the average voltage to load terminal which is shown in fig.7(a).

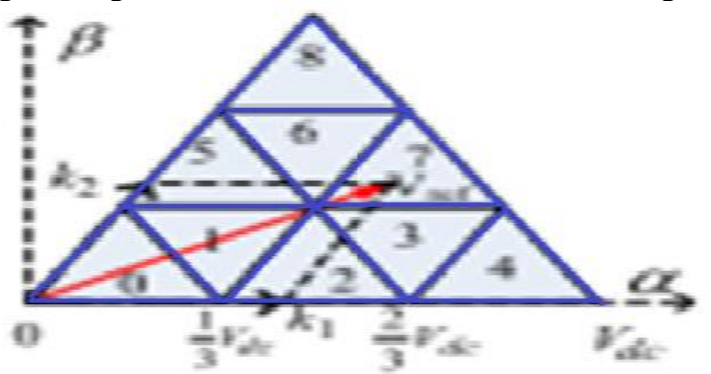

Fig.7.(b) The SVM of the dual-inverter with source ratio of 2:1.

\section{III.FUZZY LOGIC CONTROLLER}

Introduction: Fuzzy controller is a controller it is implemented with a human decision. It will be proposed by Lotfi zadhe. Fuzzy controller is used in many applications.

The fuzzy controller rules are implemented based on the membership functions (i.e true or false condition), it will operate between the real numbers [0 1 1]. The fuzzy controller block diagram is shown in below fig. 8 .

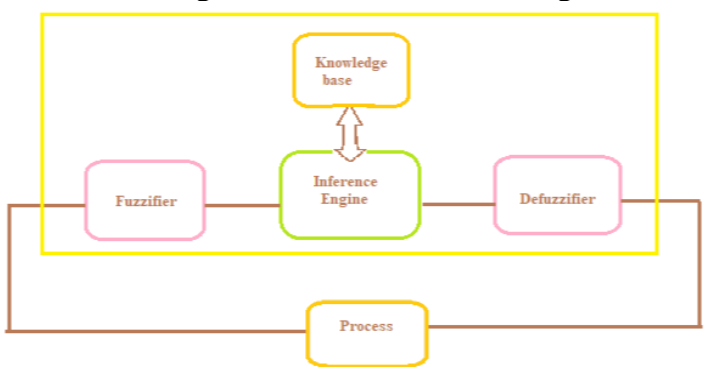

Fig.8. The fuzzy logic controller block diagram.

The fuzzy controller is analysed with three levels.

1.Input stage (fuzzification),

2. Processing stage (interference engine) and

3. Output stage (defuzzification).

Fuzzification: The conversion of crisp input value [0 1$]$ to a fuzzy value, this process is called fuzzification.

The input error for the FLC is given as

$$
\begin{aligned}
& \mathrm{E}(\mathrm{k})=\frac{\mathrm{P}_{\mathrm{ph}(\mathrm{k})}-\mathrm{P}_{\mathrm{ph}(\mathrm{k}-1)}}{\mathrm{V}_{\mathrm{ph}(\mathrm{k})}-\mathrm{V}_{\mathrm{ph}(\mathrm{k}-1)}} \\
& \mathrm{CE}(\mathrm{k})=\mathrm{E}(\mathrm{k})-\mathrm{E}(\mathrm{k}-1)
\end{aligned}
$$

Inference Method: The fuzzy rules are analysed in this method. Different composition methods are proposed for fuzzy controller. In this project Min method is used and the rules of the FLC is shown in Table 2.

Table II

Fuzzy rules

\begin{tabular}{|l|l|l|l|l|l|l|l|}
\hline ele & NB & NM & NS & ZE & PS & PM & PB \\
\hline NB & NB & NB & NB & NB & NM & NS & ZE \\
\hline NM & NB & NB & NM & NS & ZE & PS & PM \\
\hline NS & NB & NB & NM & NS & ZE & PS & PM \\
\hline ZE & NB & NM & NS & ZE & PS & PM & PB \\
\hline PS & NM & NS & ZE & PS & PM & PB & PB \\
\hline
\end{tabular}


Design and Control of Space Vector Pwm Technique with the Fuzzy Control Based Multilevel Inverter for an Open End Winding Induction Motor

\begin{tabular}{l|l|l|l|l|l|l|l|} 
PM & NS & ZE & PS & PM & PB & PB & PB \\
\hline PB & ZE & PS & PM & PB & PB & PB & PB \\
\hline
\end{tabular}

Fuzzy controller is more efficient to control the problems. By using the IF- THEN rules we can analyze the fuzzy controller.

\section{Defuzzification:}

Conversion process of fuzzy value to a real value is called defuzzification.

The set of FC rules are derived from

$\mathrm{u}=-[\alpha \mathrm{E}+(1-\alpha) * \mathrm{C}]$

Where $\alpha$ is self-adjustable factor which will control the operation. $\mathrm{E}$ is the error of the system, $\mathrm{C}$ is the change in error and $u$ is the control variable.

The membership functions of input error and change in error and output are analyzed as shown in below figures.

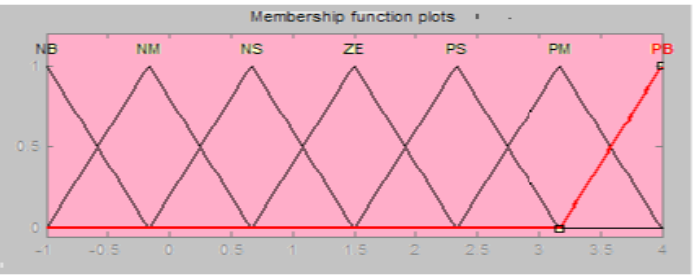

Fig.9. Membership function of input error

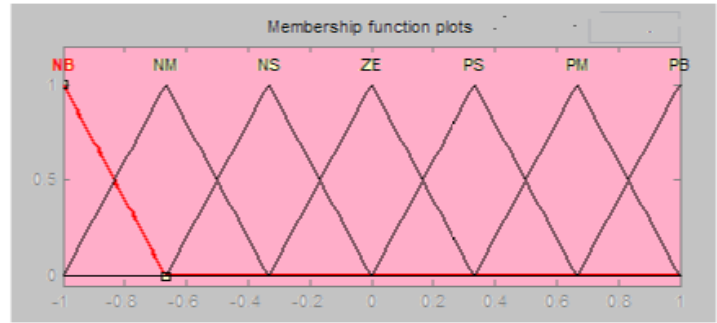

Fig.10. Membership function of change in error

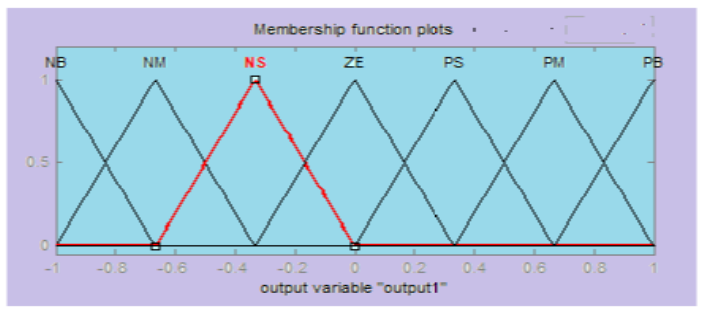

Fig.11. Membership function of output waveform

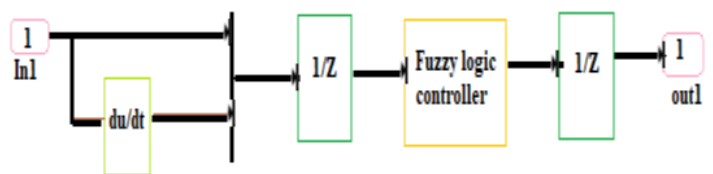

Fig.12. The simulation block diagram of FLC

\section{Fuzzy controller advantages:}

The fuzzy controller have many advantages. They are

1. The Fuzzy rules are analyzed with human decisions. So it will be easy to analyze.

2. It will be more simple and flexible.

3. The cost for development of Fuzzy controller is less.

4. Fuzzy controller is more precise.

5. It is used in HVAC applications.

Fuzzy controller applications:

The FLC is used in many applications such as

$>$ Air conditioning system

$>$ Traffic control

$>$ Vacuum cleaner

$>$ Washing machine system.
$>$ Intelligent highway system

$>$ Water purification plant control.

$>$ Satellite height control

The simulation block diagram of the proposed method is presented in fig.13.

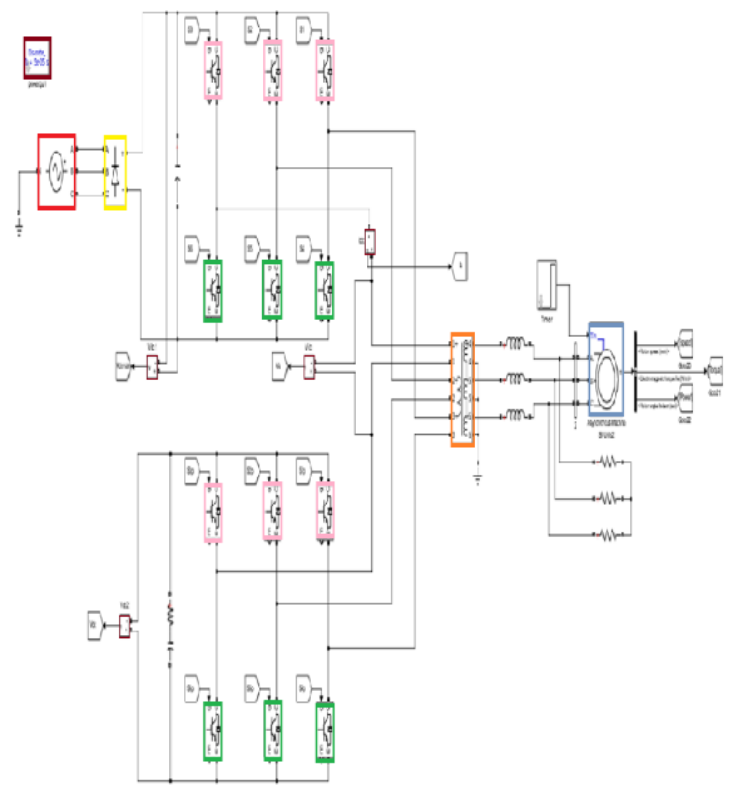

Fig. 13. The simulation block diagram of proposed technique.

\section{IV.SIMULATION RESULTS}

Loss comparison

Comparison between the inverter and losses are presented in Table.III

TABLE III

VOLTGAE COMAPARISION BETWEEN THE DEVICES

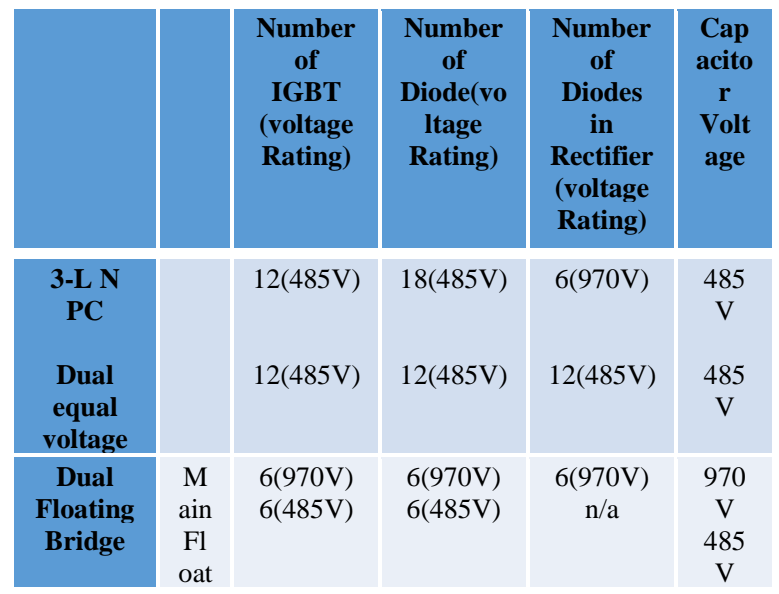

Open loop V/f controlled IM drive

By using the v/f controlled technique the IM drive is controlled, it will be shown in fig.15. In this technique the $500 \mathrm{v}$ supply is given to the main converter and switching frequency is $2 \mathrm{KHZ}$. At steady state operation, the frequency $25 \mathrm{HZ}$ is used due to hold the $\mathrm{V} / \mathrm{F}$ ratio which is rated at $690 \mathrm{~V}$. At no load the voltage and the current and the floating dc voltage are shown in fig. 14 


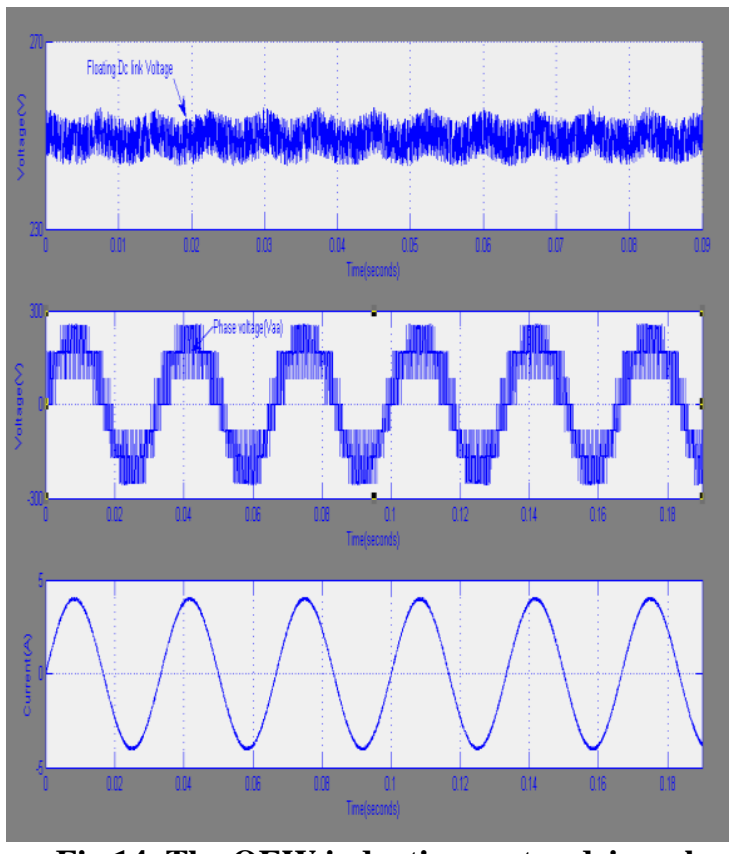

Fig.14. The OEW induction motor drive when V/F controlled technique is used. The floating capacitor voltage, the phase voltage at Vaa, and the phase current at Ia

At no load, the floating capacitor reaches to required value and also achieves a multilevel output voltage waveform. A step load is applied to a motor the overall performance of the induction motor is improved. Because of the sudden load is applied the capacitor voltage is decreased.

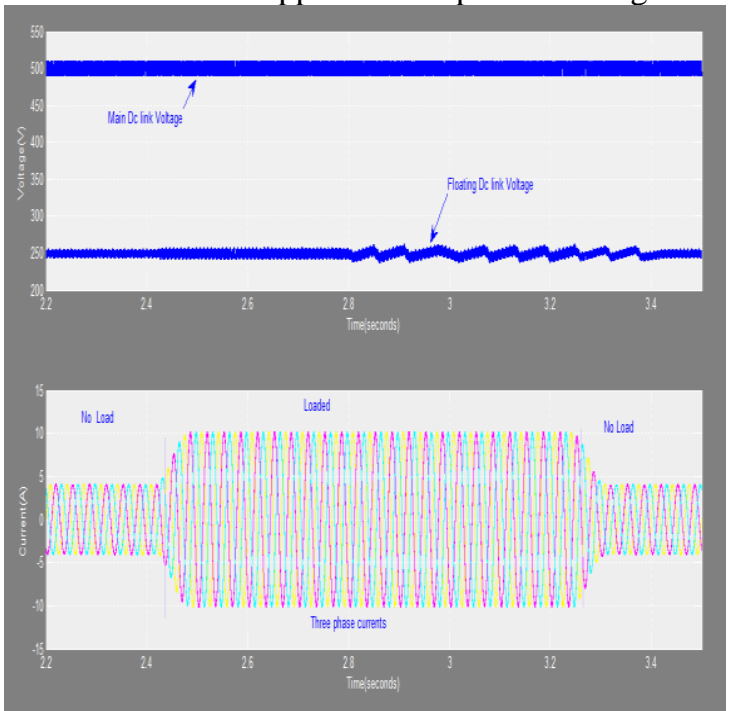

Fig.15. A step load is connected to the open loop v/f controlled motor drive the dc link voltage and the currents at three phase.

The modification of the pulses are applied to a machine then the THD of voltage and the current analyzed and the results of total harmonic distortion of voltage and the current are shown in figure.16

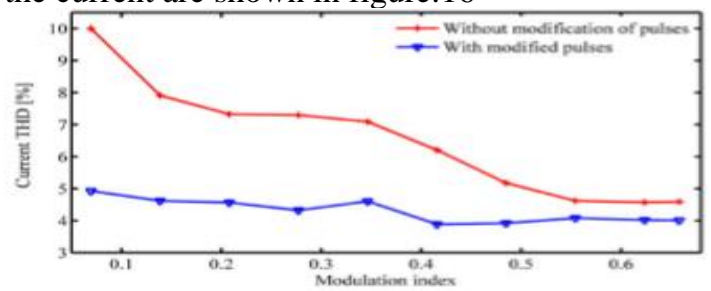

Fig. 16(a). The harmonic distortion at current

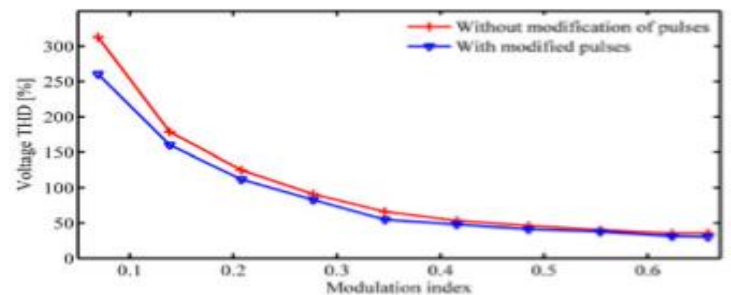

Fig. 16(b). The harmonic distortion at voltage Rotor flux orientated closed loop control:

In the proposed technique, the $500 \mathrm{~V}$ dc supply is attached to most important inverter. The main objective of the floating capacitor is to govern the voltage and the bridge capacitor have to be half of the main dc voltage. By using the rotor flux orientation approach the induction machine flux and torque generating of a current is analyzed

At initial condition, the floating capacitor is charged with reference d-axis i.e. field current. If the capacitor become charged then speed command become adjusted. An outside load is applied to the motor the floating capacitor will be effected in torque control mode. The block diagram of vector control drive is presented in fig.17.

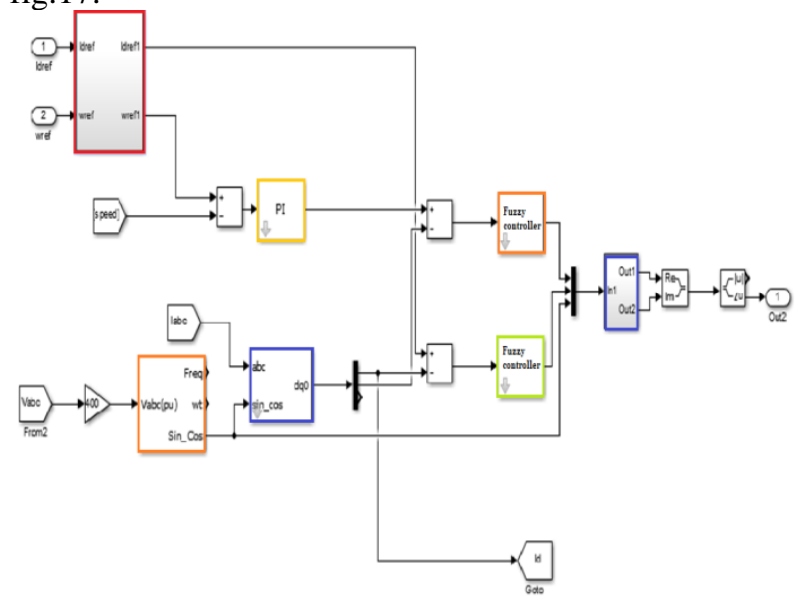

Fig. 17. The block diagram of vector control drive.

To investigate the capacitor voltage the set of FOC rules is analyzed. At the transient state, it will compares the reference voltage and actual floating capacitor voltage. The capacitor voltage is greater than the $15 \%$ of reference voltage, then device will close down. The flowchart for FOC algorithm of rules is shown in under fig.18.

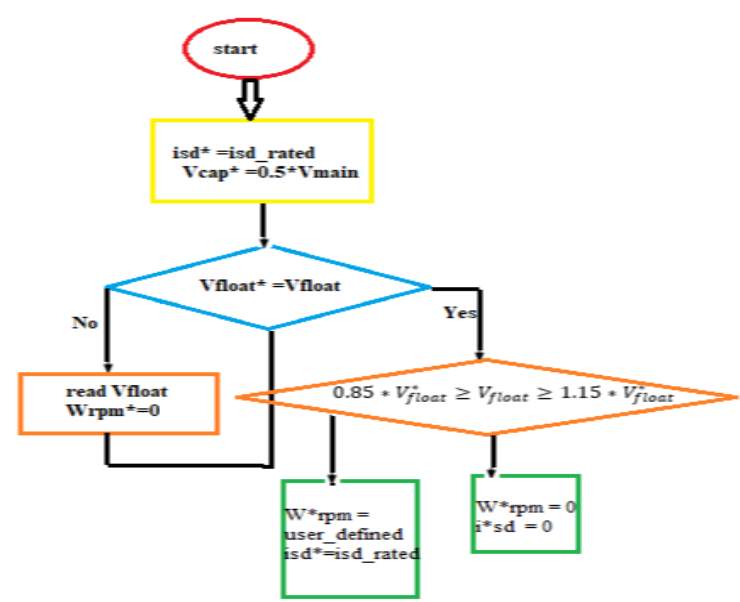

Fig. 18. FOC algorithm 
Design and Control of Space Vector Pwm Technique with the Fuzzy Control Based Multilevel Inverter for an Open End Winding Induction Motor

The parameters of power converter and induction motor as shown in Table. IV.

TABLE IV

THE PARAMETERS OF LOAD AND POWER CONVERTERS

\begin{tabular}{|l|l|l|}
\hline \multicolumn{3}{|c|}{ INDUCTION MOTOR } \\
\hline stator resistance & $\mathrm{Rs}$ & $1.4 \Omega$ \\
\hline Rotor resistance & $\mathrm{Rr}$ & $1.02 \Omega$ \\
\hline Stator leakage inductance & $\mathrm{L} 1 \Omega$ & $0.0115 \mathrm{H}$ \\
\hline Rotor leakage inductance & $\mathrm{L} 1 \mathrm{r}$ & $0.009258 \mathrm{H}$ \\
\hline Magnetizing inductance & $\mathrm{Lm}$ & $0.2258 \mathrm{H}$ \\
\hline \multicolumn{2}{|c|}{ POWER CONVERTER } & \\
\hline \multicolumn{1}{|c|}{ Main dc link } & $\mathrm{Vdc}$ & $500 \mathrm{~V}$ \\
\hline Floating dc link & $\mathrm{Vf}$ & $250 \mathrm{~V}$ \\
\hline Main dc link capacitance & $\mathrm{Cm}$ & $1250 \mu \mathrm{F}$ \\
\hline $\begin{array}{l}\text { Floating link } \\
\text { capacitance }\end{array}$ & $\mathrm{Cf}$ & $3250 \mu \mathrm{F}$ \\
\hline $\begin{array}{l}\text { Gating pulses propagation } \\
\text { delay }\end{array}$ & & $0.1-0.2 \mu \mathrm{s}$ \\
\hline On board dead time & $\mathrm{Dr}$ & $4-4.1 \mu \mathrm{s}$ \\
\hline Snubber capacitance & $\mathrm{Cs}$ & $0.7 \mathrm{Nf}$ \\
\hline $\begin{array}{l}\text { Output common mode } \\
\text { inductance }\end{array}$ & Lo & $5 \mu \mathrm{H}$ \\
\hline$\quad$ To charge the Cap & & \\
\hline
\end{tabular}

To charge the capacitor first of all, the system changed into magnetized first. After the magnetization process completed, a step load is applied as shown in fig.19

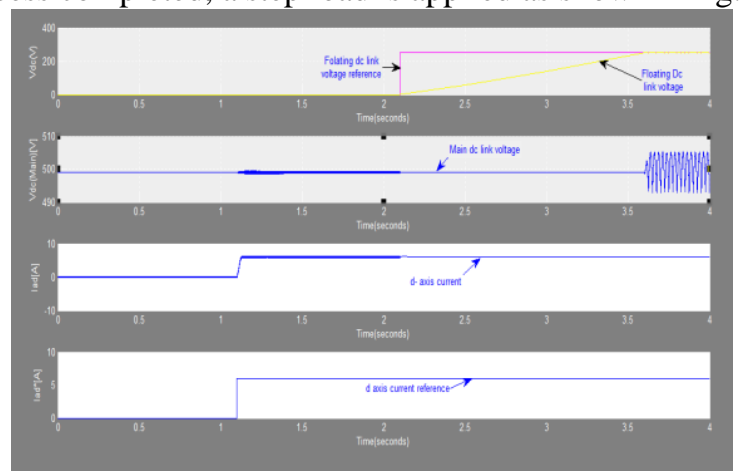

Fig. 19 The floating capacitor voltage and reference when the system is magnetized, the dc link voltage, the current at $\mathbf{d}$-axis and the current reference at $\mathbf{d}$-axis.

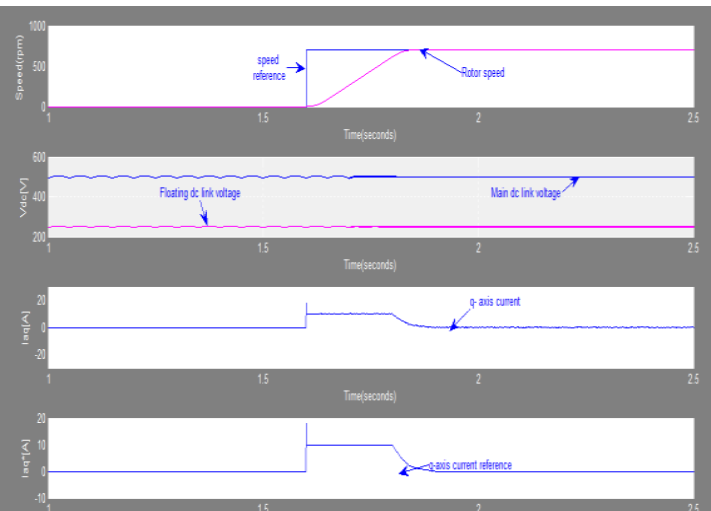

Fig. 20. Rotor speed with reference at no load to step load under FOC, the floating capacitor and the main dclink capacitor voltage, the current at $q$-axis, and the reference current at $q$-axis.
The machine is drawing only reactive power for maintain a constant electromagnetic field. The rotor was at stand still and for maintain the constant electromagnetic condition, the machine is drawing active power when the rotor is standstill condition.

The capacitor is discharged when the power supply is given to main converter at this situation. The reference torque current $\mathrm{i} * \mathrm{q}$ is as shown in Fig. 21.

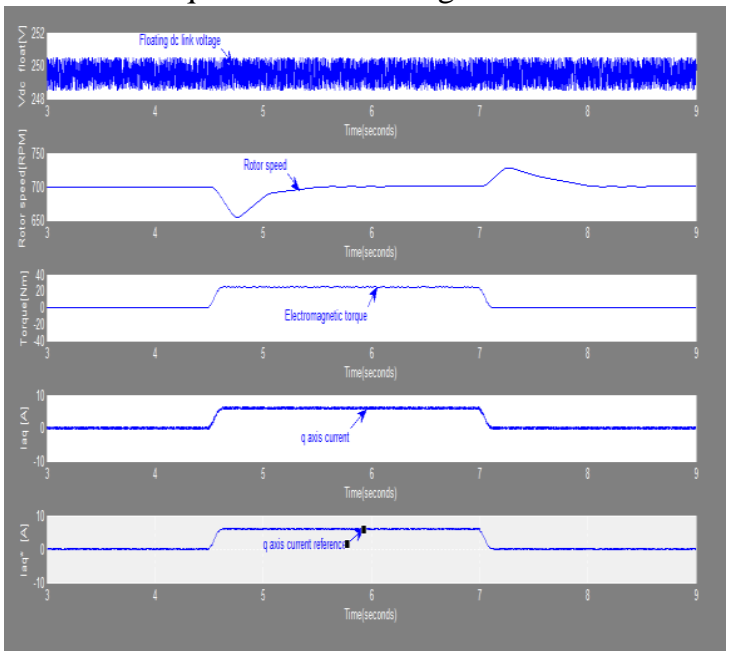

Fig. 21. Step load is implemented under FOC the speed reaches steady state. The floating capacitor voltage, the rotor speed, the electromagnetic torque, the current at $q$ -axis, and the reference current at $q$-axis TABLE.V

COMPARISION B/W PI AND FUZZY CONTROLLER

\begin{tabular}{|l|l|l|}
\hline & \multicolumn{1}{|c|}{ PI } & Fuzzy \\
\hline Vdc & $80.31 \%$ & $77.21 \%$ \\
\hline Vdc main & $25.41 \%$ & $24.77 \%$ \\
\hline Id & $66.91 \%$ & $64.54 \%$ \\
\hline
\end{tabular}

The capacitor voltage increases at no load condition and real power flowing through the device. When the load is connected to a machine the phase voltage, phase current and floating dc link voltage as shown in fig.22

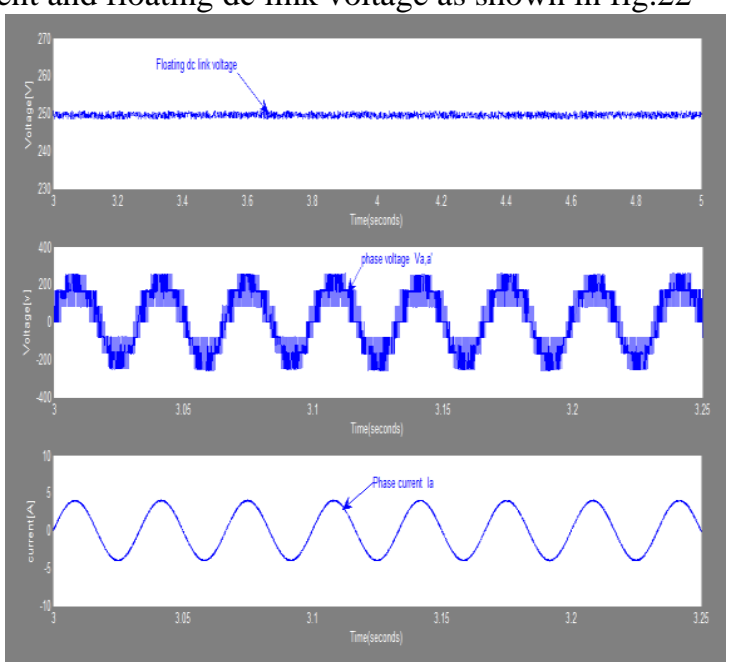

Fig. 22. When the machine is connected, the Phase voltage and current under FOC. The floating dc-link voltage, the phase voltage at Vaa, and the phase current at Ia. 


\section{V.CONCULSION}

The three phase OEW induction motor drive with fuzzy control based multilevel inverter is proposed in project. By using these paper we can achieve the multilevel output voltage and reducing the losses by using fuzzy controller. The proposed method have only one dc voltage source is connected dual inverter of open end winding IM. The fuzzy controller is implemented based on human decisions so we can analyze the rules easily and reduce the distortions of proposed method. The cost is less for development of fuzzy controller and more precise. In the proposed method we can eliminate the isolation transformer and improve the waveform quality using the SVM. By using the SVM the switching states are analyzed which reduce the unwanted voltage levels and also improve the waveform quality. Among the different ways of adopting these PWM techniques space vector based implementation has many advantages. Out of which, dc bus utilization, ease of digital implementation and freedom in selection of zero states are the major concerns. The fuzzy controller mainly used in different applications. The proposed method is analyzed using the simulation results.

\section{REFERENCES}

1. The digital implementation of SVM pulse width modulation technique with a configuration of an OEW induction motor using the dual inverter.

2. "Triangle evaluation and SV strategies of pulse width modulation in inverter-fed drives,” J. Indian Inst. Vol. Eighty, pp. 409-427, Sep/Oct. 2000.

3. "SVPWM techniques for an enhanced performance for the four-level Open-end Winding Induction Motor drive," IEEE Trans. Ind. Electron., vol. Sixty four, no. Four, pp. 2750-2759, April 2017.

4. "Space Vector PWM control of dual inverter fed open-end winding induction motor drive", Proc. power Electronics Conf. (APEC), pp. 399-405.

5. "High efficiency and low acoustic noise drive the usage of open winding ac motor and space Vector Modulated Inverters," IEEE Trans. Ind. Electron. Vol. 49pp 783 - 789 Aug.

6. Impact of zero Vector Placement in a dual inverter fed open-end winding induction motor drive with a Decoupled space Vector PWM strategy," IEEE Transactions on industrial Electronics Vol. 55, No.6 Modulation and control of multilevel inverter for an open end winding induction motor with dual Inverter.

8. Overall performance evaluation of space vector pulse width modulation on v/f controller based open end winding induction motor. 